\title{
The Origin and In Situ Identification of Uncultured Gut Bacteria in Fourth-Instar Larvae of the Red Imported Fire Ant, Solenopsis invicta (Hymenoptera: Formicidae)
}

by

Albert H. Lee ${ }^{1} \&$ Linda Hooper-Bui ${ }^{2}$

ABSTRACT

This study corroborated the findings of Lee et al. (2008) and relied on culture-independent techniques, particularly $16 \mathrm{~S}$ rDNA sequencing. Results from the study demonstrated that ants in captivity completely change their gut bacterial diversity strongly supports the conclusion that fire ant gut bacteria are environmental in origin. Bacteria in the fourth-instar larvae were present because they were consumed with food sources. From molecular data, a differing list of bacteria from each colony with different branching and clustering among bacterial clades in the phylogenetic trees were found. Different bacterial diversity and evenness was found in all colonies, which provided evidence against the idea of the presence of obligate bactrial endosymbionts in Solenopis invicta guts. Obligate endosymbiont elimination through the use of broad-spectrum antibiotics did not significant affect ant mortality when compared to the untreated controls. This study did not find bacteriocytes in the midgut epithelium of fire ants. Microscopic observations did not locate any bacteriocytes in fourth-instar $S$. invicta larvae. All identified bacteria appeared to have been derived from the food or the environment. Though coadapted bacteria and specialized bacteriocytes were not found in the guts of fourth-instar larvae, such specialized organisms may be present elsewhere in the ant. Coadapted symbionts may exist in other parts of the larvae's body or in other stages of development.

Key words: bacteria, symbiosis, Solenopsis invicta

Louisiana State University Agricultural Center

404 Life Science Building, LSU. Baton Rouge, La 70808

${ }^{1}$ Leeahy@gmail.com

22Hooper@agcenter.lsu.edu 


\section{INTRODUCTION}

Lee et al. (2008) recently described culture-independent identification of gut bacteria in fourth-instar larvae of the red imported fire ant, Solenopsis invicta Buren. They identified bacteria communities in three locations across Louisiana with culture-independent methods in an attempt to identify coadapted mutualistic microorganisms. The data from the earlier study suggest that such organisms are not present in the guts of $S$. invicta larvae, and that the origin of the bacteria in the guts is environmental (Lee et al. 2008). Culture-independent molecular techniques, which they used, are a valuable tool in identifying unknown bacteria because they do not rely on selective conditions such as media (Lee et al. 2008). In an effort to verify the observation made by Lee et al. (2008), three studies were conducted to further explore the possibility of coadapted mutualistic bacteria in $S$. invicta larvae guts, as well as identifying potential origins.

Symbiotic associations between organisms are common, and these associations are described as an interaction between multiple organisms living together in intimate association (inside or on the body), or even the merging of two dissimilar organisms (Sapp 1994). One type of symbiosis is endosymbiosis. This term refers to an organism associated internally within another organism (e.g. intracellular, inside guts).

Peloquin \& Greenberg (2003) investigated bacteria from fire ant guts by culturing gut contents on nutrient and blood agar. Data from Lee et al. (2008) suggested that their bacterial inventory may be incomplete due to the selective nature of growth media. Additionally, Li et al. (2005), used selective methods to grow bacteria from fire ants and used molecular techniques to identify what they grew. More than $85 \%$ of known naturally occurring bacteria cannot be cultured with currently available techniques (Liu et al. 1997). Lee et al. (2008) found 65 species of bacteria. As demonstrated by Lee et al. (2008), culture-independent molecular techniques provide an opportunity to describe microbial diversity without the need to culture live bacteria (Urakawa et al. 1999). These techniques remove biases associated with culturing and provide a comparatively unbiased inventory. The most common molecular approach to identifying yet-to-be cultured bacteria is to sequence the 16S rRNA gene (Liu et al. 1997). Gene sequences can then be 
compared to the public database GenBank through BLAST (Altschul et al. 1990) to identify the bacteria.

Microbial communities in S. invicta were investigated since this invasive ant has the capacity to greatly affect the environment, wildlife, and other invertebrates. The red imported fire ant is a medical, urban, and agricultural pest from South America. It has invaded the southern states of the US, California, Puerto Rico, Australia, Taiwan, and China. These invasive ants are successful because of their preference for disturbed habitats, high reproductive rates, and ability to feed on a wide variety of food items (Vinson \& Greenberg 1986). Fire ants have painful stings that are a serious health concern for people living in their invaded range. Any new biological or physiological information may provide insight into their biology and could lead to research on control. The first steps in these investigations are to determine which microbes are important to Solenopsis invicta and whether or not they are obligate or transient.

The microbes in fire ants may provide an opportunity to control these invasive ants. Most fire ant management techniques capitalize on fire ant foraging behavior in which the adult worker ants leave the nest in search of food. Workers will find many food types but only consume liquids or minute particles due to their "waist." They bring solid items to the fourth-instar larvae to be liquefied by digestive enzymes secreted externally (Cassill \& Tschinkel 1995). Investigation on this stage of larvae was emphasized to determine if their guts harbored symbiotic bacteria involved in nutrient distribution.

The goal of the experiment was to determine if a laboratory diet, which differed from that on which the insects fed in the field, affected the bacterial community in the $S$. invicta larvae. That question was addressed with a study which focused on an ant colony that was observed in the published study (Lee et al. 2008) and was maintained in the laboratory for two and a half months. The three colonies tested by Lee et al. (2008) harbored different sets of bacteria in the guts of their fourth-instar larvae; this suggested that the bacteria communities can be changed based on what is fed to the ants. Colonies from each unique location in Louisiana were exposed to unique environmental conditions. Since the bacterial communities appeared to be determined by foods and environment, it would be logical to examine the foods fed to the ants to see if the bacteria were transferred. A logical conclusion would be that bacteria found in ants in captivity would be different 
from the time when they were first brought in to the lab due to differences in the environment.

Despite the great power of molecular techniques, they do have limitations in that abundant DNA templates can mask the presence of less abundant ones during amplification. If a bacterium was not represented by a clone in the library that does not necessarily mean that it is not present in the gut microbial community. This leaves the possibility that the presence of symbionts may be masked by the environmentally-derived bacteria. Due to this possibility, the problem was investigated with different tactics. Ant colony fragments were treated with several broad-spectrum antibiotics and their mortality was studied versus an untreated control. Coadapted obligate mutualistic microorganisms, if eliminated, should increase the mortality of $S$. invicta workers.

Sauer et al. (2002) found that the "Candidatus Blochmannia floridanus endosymbiont" in the ant Camponotus floridanus is most important during embryogenesis and larval development. Elimination of these endosymbionts from the oocytes had a negative effect on embryogenesis and larval development. This is reflected in reduced brood and an increase in mortality of adult ants. Ants in the tribe Cephalotini have specialized structures in their digestive tract that harbor bacteria (Caetano 1989). These bacteria are facultative anaerobic bacteria with digestive functions (Yurman \& Dominiquez-Bello 1993). Like the carpenter ants, these ants have bacteriocytes with obligate endosymbionts. Jaffe (2001) fed antibiotics to Cephalotes pusillus and found an increase in mortality. The researchers concluded that some of the bacteria in the digestive tract of $C$. pusillus were essential to the ant, probably forming a symbiotic relationship with their host. Elimination of such bacteria caused an increase in mortality. Similarly, if $S$. invicta are treated with antibiotics and mortality is increased, then a similar set of obligate endosymbionts may be in S. invicta . If mortality is no different from controls then the presented results will be more evidence rejecting the idea of obligate endosymbionts in S. invicta .

Camponotusfloridanus was found to have bacteriocytes containingobligate endosymbionts through the use of transmission microscopy (Sauer et al.2002). Obligate symbionts have been found in several ant species to supplement specialized diets. Bacteriocytes in the carpenter ant midgut epithelium were full of endosymbiotic bacteria. Sauer et al. (2002) believed that the "Candidatus 
Blochmannia floridanus endosymbiont" in the ant of the species C. floridanus is most important during embryogenesis and larval development. Adult ants are able to live without their bacterial endosymbionts under laboratory conditions. These symbionts seem to degenerate naturally over time, as observed in older queens, suggesting that the symbiosis may be of relevance during the early stages of the ants' development (Sauer et al. 2002).

The omnivorous $C$. floridanus is also capable of feeding almost exclusively on sugary fluids due to their symbionts. Candidatus Blochmanniafloridanus is able to supply nitrogen and sulfur compounds to the host through the host's metabolic machinery (Gil et al. 2003). Members of the genus Candidatus Blochmannia are closely related to other endosymbiotic bacteria of insects such as Buchnera of aphids, Wigglesworthia of tsetse flies, and, more distantly, Carsonella of psyllids. These bacteria form a clade contained within the family Enterobacteriaceae within the phylum Proteobacteria (Sauer et al. 2002).

The presence of bacteriocytes and the visibility of the bacteria provided unquestionable proof of the presence of endosymbiotic bacteria in other ants. Fourth-instar larvae of red imported fire ants, the stage that can process solid foods (Vinson \& Sorenson 1986) was the focus of this study. After experimenting with culture-independent methods and antibiotic mortality tests, the next step was to physically examine the guts of larvae and search for bacteriocytes similar to those found in $C$. floridanus.

\section{MATERIALS AND METHODS}

\section{Antibiotic Efficacy}

At the beginning of the experiment, larvae were collected and their guts aseptically removed and plated on BHI and BHI-kanamycin media. This was done to check for the antibiotics' effectiveness at killing bacteria. The same was done on day 13 and day 25 to check for antibiotic resistance.

\section{Effect of Laboratory Diet}

Of the three colonies used by Lee et al. (2008), the colony from Bogalusa was the only one that still had queens and brood after two and a half months in captivity. As the sole-survivor of the three colonies initially studied, it could be accessed again for a follow-up analysis. Fire ant colonies were reared in plastic boxes with Teflon as described in Lee et al. (2008). Food and water 
were provided in the form of dead crickets, tap water, and 50\% sugar water. Rearing methods were based on the protocol described by Banks et al. (1981). All food sources and water were replenished as needed.

All the available fourth-instar larvae (32) were taken out of the colony followed by aseptic isolation of their guts. Larval guts were then homogenized in a common reaction tube and bacteria DNA was extracted with the Qiagen DNeasy Tissue kit. The DNA was used as a template to perform 16S rDNA PCR utilizing the methods described in Lee et al. (2008). Amplification was done with the universal 16S rRNA primers $27 \mathrm{~F}$ and 1492R (Lane 1991). PCR products were purified and a clone library was established utilizing $E$. coli. Clones with the 16S rDNA were selected and M13 PCR was performed to amplify the DNA of interest. The Li-Cor 4300 DNA Analyzer used to sequence the colonies described in Lee et al. (2008) was malfunctioning at this point in the experiment so amplified ribosomal DNA restriction analysis (ARDRA) was used in conjunction with a commercial sequencing service. Detailed description of methods used for DNA extraction, PCR, cloning, phylogenetic tree construction, and species accumulation curve construction can be found in Lee et al. (2008).

ARDRA required the $16 \mathrm{~S}$ rDNA fragments to be restricted to create unique banding patterns. Purified $16 \mathrm{~S}$ rDNA products were digested with HaeIII and RsaI restriction enzymes to generate banding patterns for each clone. Each digestion reaction contained $15 \mu \mathrm{L}$ of PCR product, $2 \mu \mathrm{L}$ of 10X NEBuffer 1 (New England Biolabs, Beverly, Massachusetts), $3 \mu \mathrm{L}$ PCR quality water, $0.25 \mu \mathrm{L}$ of $R s a \mathrm{I}$ (2.5 units), and $0.25 \mu \mathrm{L}$ of Hae III (2.5 units). Each reaction was incubated in an MJ Research PTC-200 Peltier Thermal Cycler. The incubation program consisted of $2 \mathrm{~h}$ at $37^{\circ} \mathrm{C}, 20 \mathrm{~min}$ at $80^{\circ} \mathrm{C}$, and finally a storage temperature of $4^{\circ} \mathrm{C}$. Incubated products were then loaded onto a $1 \%$ agarose gel and banding patterns were examined visually. Clones with unique patterns were isolated and sequenced at the University of California, Riverside's Core Instrumentation Facility. Once the sequences were returned, Vector NTI version 7 was used to form contiguous sequences. Sequences were then compared to entries in GenBank through BLAST. Once clone identities were established, a phylogenetic tree and species accumulation curves were created using MEGA 3.1 (Kumar et al. 2004) and EstimateS (Colwell 1994-2004), respectively. 


\section{Antibiotic Trials}

An ant colony fragment from an established laboratory colony was used. This colony was field-collected on February 23, 2005 (469 days). Multiple queens and a large number of brood were available in the colony. Larvae were numerous enough for the three treatments and controls, each with ten replicate colony fragments.

Three treatment sets represent the three antibiotics tested. Each replicate had colony fragments of $\sim 50-100$ workers (counted at the end of the study), and five fourth-instar larvae and about ten larvae with an approximate age of first to third instars. Control colony fragments consisted of one set with ten boxes (replicates) and were set up similar to treatment boxes. Each treated colony fragment received water and antibiotics suspended in $50 \%$ sugar water, and freshly killed crickets. All food and water resources were replenished every day except for crickets. Crickets were replaced when consumed or after one week. Control colonies were not provided antibiotic solutions but were given all of the other food and water resources.

Plastic boxes $(17 \times 8 \times 4 \mathrm{~cm})$ were coated with Teflon to prevent the ants from escaping the experimental enclosure. For treatment colony fragments, each coated box was furnished with two crushed crickets, $900 \mu \mathrm{l}$ of water and $900 \mu \mathrm{l}$ of $5 \%$ antibiotic solution (in treatments only) mixed with $50 \%$ sugar water in $6 \times 50 \mathrm{~mm}$ Borosilicate culture tubes plugged with moist cotton. Harborage sites were provided for all colony fragments in the form of plaster of Paris nests. Each nest was constructed from a Petri dish $(3.5 \mathrm{~cm}$ in diameter) filled half-way with plaster of Paris. A cotton shoestring $(\sim 6 \mathrm{~cm})$ was partially embedded in the plaster to facilitate moistening of the plate without disturbing the ants. Once dry, the sides of the dishes were drilled to provide entry holes for the ants.

Three antibiotics were tested in this study; these included kanamycin, tetracycline, and rifampicin. The antibiotic was found to be effective against the endosymbionts of those ants. Antibiotics were mixed with 50\% sugar water to produce a $5 \%$ antibiotic solution.

Worker mortality was counted every day until the last larva pupated. The last larva pupated after 28 days of observation. Dead ants were removed from each box after they were counted. At the end of the experiment, the live ants were killed and counted to determine the total number of ants in each repli- 
cate for mortality percentages. SAS version 9.1 (SAS Institute Inc. 2002) was used to determine statistical differences between control and treated colonies. PROC-GLM was used to generate the residuals and UNIVARIATE procedure was used to determine normality. The data passed the test for normality (SAS Institute 2002). Mortality of antibiotic-treated adult ants for each day was compared to each other and the control using PROC-MIXED, which included an analysis of variance (ANOVA) and the Tukey-Kramer analysis. Larvae were examined and counted every day; once they all eclosed as adults the replicate was terminated.

\section{Microscopy}

The ants used were from an established laboratory colony from February 23, 2005 and the experiment began on April 16, 2007 (782 days post collection). Twenty fourth-instar larvae were taken from the colony and dissected for microscopy. The Louisiana State University's Socolofsky Microscopy Center prepared the samples and processed the larval guts for microscopy after aseptic removal of the guts. Multiple guts (five) were submitted to the facility to compensate for any errors that may occur during microscopy preparation. Four gut samples were used to take images. Light and electron microscopy were used to examine gut structures. Three ant guts provided the best images with the clearest structures.

Entire guts of $S$. invicta fourth-instar larvae guts were pulled out and fixed in $2.5 \%$ glutaraldehyde and $1 \%$ paraformadehyde in $0.2 \mathrm{M}$ cacodylate buffer ( $\mathrm{pH} 7.2)$ and incubated at room temperature for 2 hours. After the incubation period, the mixture was post-fixed in $1 \%$ osmium tetroxide $\left(\mathrm{OsO}_{4}\right)$ buffer for one hour, followed by a $0.1 \mathrm{M}$ cacodylate buffer wash. Upon completion of the wash, the mixture was placed in $1 \%$ uranyl acetate for block staining. The materials were dehydrated in an ethanol series and embedded in medium grade LR White Resin (London Resin Company Ltd., England). Once in place, the resin was dried in carbon dioxide using a Denton DCP-1 critical point drying apparatus. Blocks of resin were cut with a microtome to produce $90 \mathrm{~nm}$ thin sections. Thin sections were stained with lead citrate and then examined with a JEOL JEM 100CX transmission electron microscope (TEM). The same preparations were also used for standard light microscopy.

Two ant guts were successfully prepared for scanning electron microscopy (SEM). They were fixed and dehydrated with the same methods described 
above. The guts were mounted on stubs, dissected, and coated with $25 \mathrm{~nm}$ of gold palladium using a Hummer II sputter coater, and examined on a Cambridge S-260 scanning electron microscope.

\section{RESULTS}

\section{Effect of the laboratory diet}

Bacteria initially found in the ants when they were collected in the field were no longer present after being reared in the laboratory (Tables 1 and 2). The species accumulation Chaol curve of the lab-reared colony (Fig. 1) leveled off at sample 111, which suggested that increased sampling should not reveal more bacteria species. Chaol indicated that between $47-96 \%$ of the actual bacterial richness was identified. The percentage range was obtained by dividing the number of unique species by the lower and upper bounds of the Chao 1 estimator $95 \%$ confidence interval. Rare-species based estimator Jack 1 indicated that between $56-77 \%$ of the bacterial richness was identified. Both the ACE and ICE estimators indicated that about 47-57\% of the bacterial richness was identified.

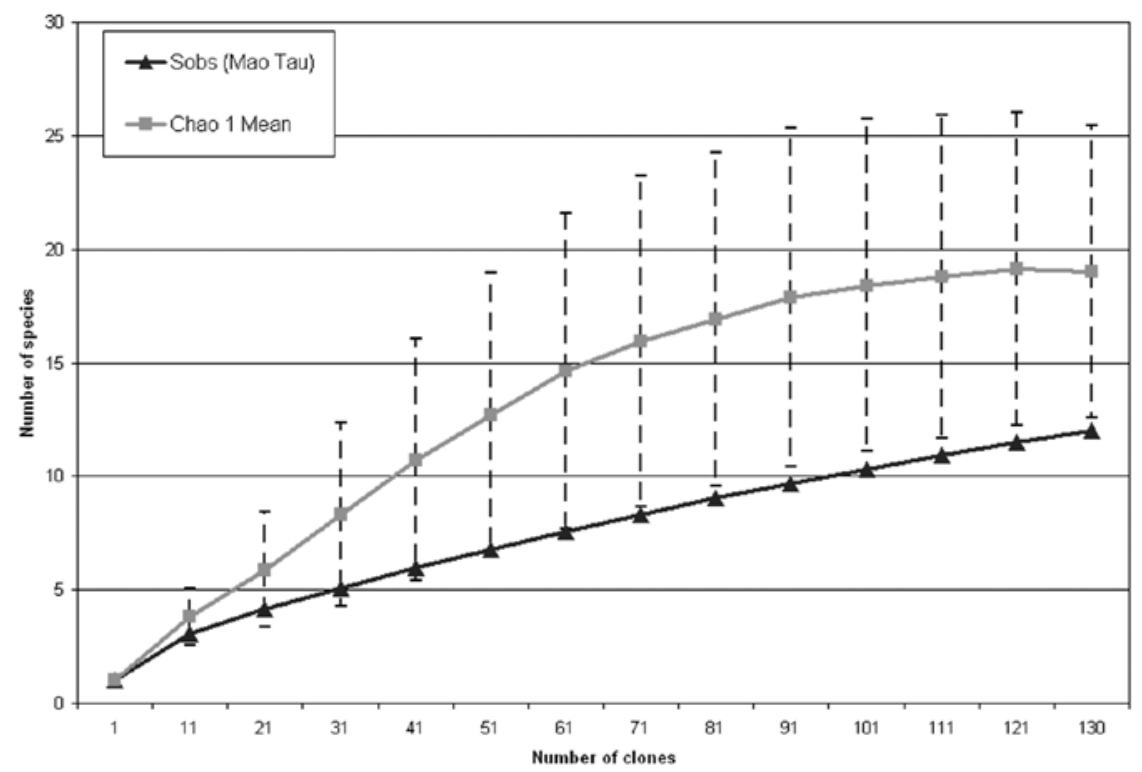

Fig. 1. Species accumulation analysis of the $16 \mathrm{~S}$ rDNA clone library from the lab-reared Bogalusa S. invicta colony 
Table 1. NCBI BLAST results for the $16 \mathrm{~S}$ rRNA gene from 130 clones from the colony collected from the lab-reared Bogalusa colony.

\begin{tabular}{llll}
\hline \hline Closest match in GenBank & $\begin{array}{l}\text { Accession } \\
\text { Number }\end{array}$ & $\begin{array}{l}\text { \% identity to } \\
\text { closest match }\end{array}$ & $\begin{array}{l}\text { Number of } \\
\text { Clones }\end{array}$ \\
\hline Enterobacter cloacae & AJ251469 & $>99 \%$ & 86 \\
Lactococcus garvieae isolate 36 & AY946285 & $>99 \%$ & 29 \\
Citrobacter freundii strain BRN1 & DQ517285 & $>99 \%$ & 3 \\
Enterococcus faecalis ATCC 19433 & DQ411814 & $>99 \%$ & 2 \\
Enterobacter cloacae subspecies dissolvens & DQ988253 & $>99 \%$ & 2 \\
Uncultured bacterium P2D1-740 & EF510442 & $>99 \%$ & 2 \\
Lactococcus garvieae NRIC 0612 & AB267905 & $>99 \%$ & 1 \\
Enterococcus faecalis TUA 2495L & AB098122 & $>99 \%$ & 1 \\
Bacterium spbL1 type3-1 & DQ321639 & $>99 \%$ & 1 \\
Klebsiella sp. GR9 & DQ100465 & $>99 \%$ & 1 \\
Enterobacter aerogenes taxon 548 & AF395913 & $>99 \%$ & 1 \\
Uncultured bacterium rRNA238 & AY959011 & $>99 \%$ & 1 \\
\hline $\begin{array}{l}\text { The name, accession numbers, closest matches in Genbank, and the number of clones identified to the species } \\
\text { (category) are displayed. }\end{array}$ & & \\
\hline \hline
\end{tabular}

Table 2. NCBI BLAST results for the $16 \mathrm{~S}$ rRNA gene from 104 clones from the field-fresh colony collected from Bogalusa.

\begin{tabular}{llll}
\hline \hline Closest match in GenBank & $\begin{array}{l}\text { Accession } \\
\text { Number }\end{array}$ & $\begin{array}{l}\text { \% identity to } \\
\text { closest match }\end{array}$ & $\begin{array}{l}\text { Number of } \\
\text { Clones }\end{array}$ \\
\hline Uncultured bacterium f4s2 & DQ068792 & $>99 \%$ & 94 \\
Bacterium 2-4 & DQ163943 & $>99 \%$ & 3 \\
Kluyvera cryocrescens 27 & AY946284 & $>99 \%$ & 1 \\
Pseudomonas fluorescens OST-5 & DQ439976 & $>99 \%$ & 1 \\
Acinetobacter sp. DSM 590 & X81659 & $>99 \%$ & 1 \\
Serratia marcescens KRED & AB061685 & $>99 \%$ & 1 \\
Klebsiella pneumoniae 573 & AY830396 & $>99 \%$ & 1 \\
Serratia marcescens CPO1(4) & AJ296308 & $>99 \%$ & 1 \\
Uncultured bacterium f6s10 & DQ068816 & $>99 \%$ & 1 \\
\hline $\begin{array}{l}\text { The name, accession numbers, closest matches in Genbank, and the number of clones identified to the species } \\
\text { (category) are displayed. (Data from Lee } \text { et al. 2008) }\end{array}$ \\
\hline \hline
\end{tabular}


Bacteria from this colony were not closely related to the symbionts of carpenter ants, aphids, and tsetse flies, which formed a unique and well-supported branch in the phylogenetic tree (Fig. 2). Tree ant (Tetraponera spp.) symbionts were found in neighboring clades.

\section{Antibiotic trials}

Mortality occurred evenly throughout the experiment (Fig. 3), and survivorship curves represented type II mortality survivorship (Fig. 4). Larvae were not attacked or eaten by the adult ants. Larval remains were not found in any of the boxes. The controls had a worker mortality range between $30-93 \%$ after 28 days; mortality values averaged $78 \%$ when the experiment ended. Ants that were given tetracycline exhibited a mortality range between $68-98 \%$ with an average of $83 \%$ at the end of the data collection period. Ants treated with kanamycin experienced a mortality range of $25-98 \%$ with an av-

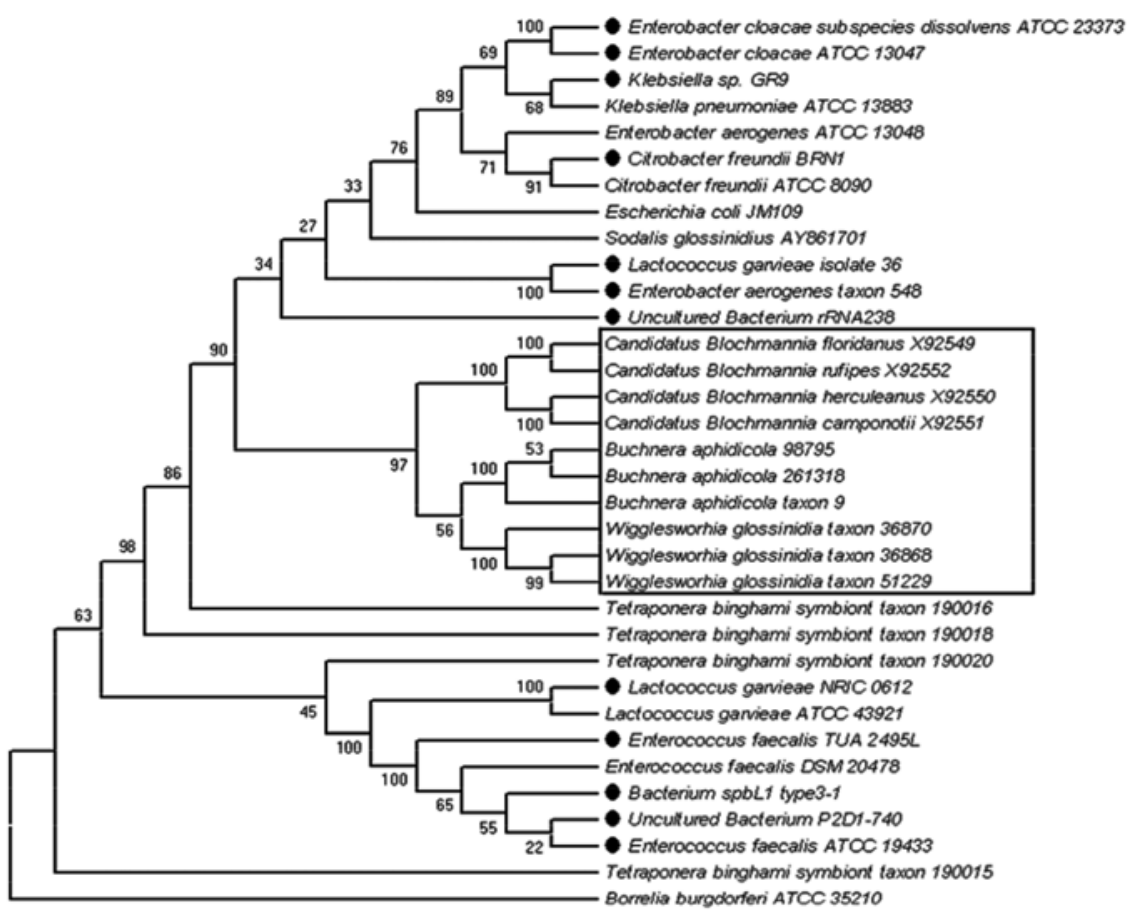

Fig. 2. Phylogenetic affiliation of the bacteria found in the Bogalusa colony after 82 days. after 82 days. Dotted species represent bacteria found in the lab-reared colony. All other entries are type strains or endosymbionts found in other insects. 


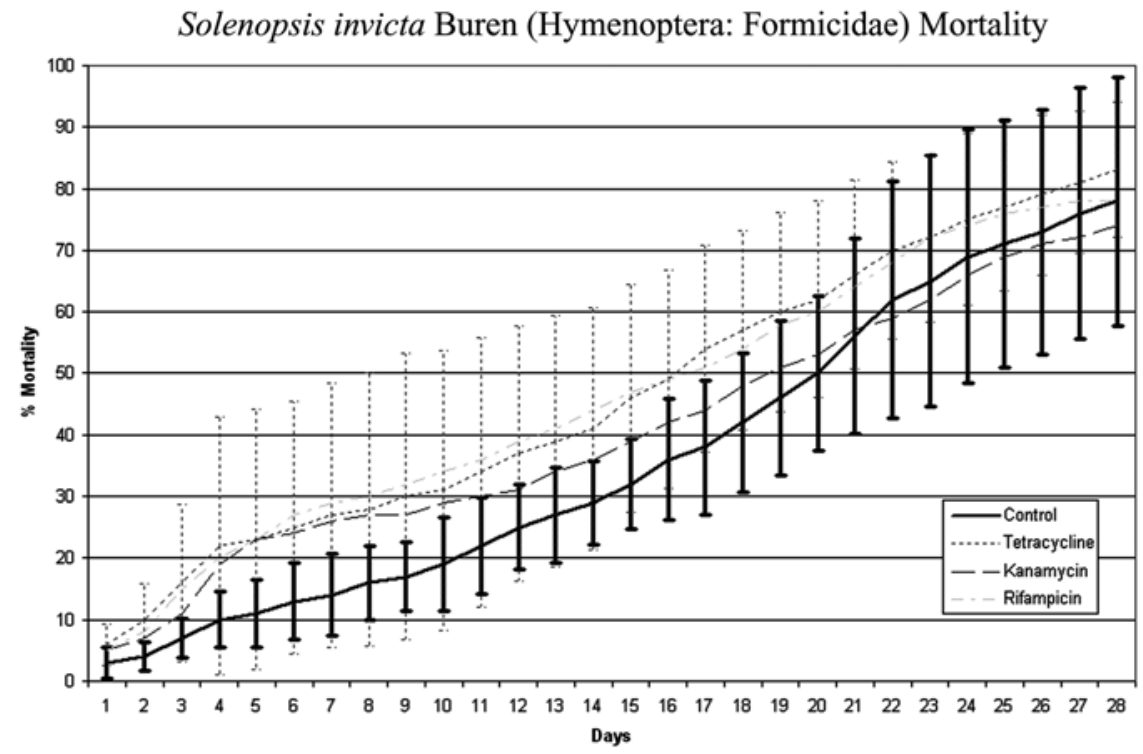

Fig. 3. Mortality curve of untreated and treated S. invicta.

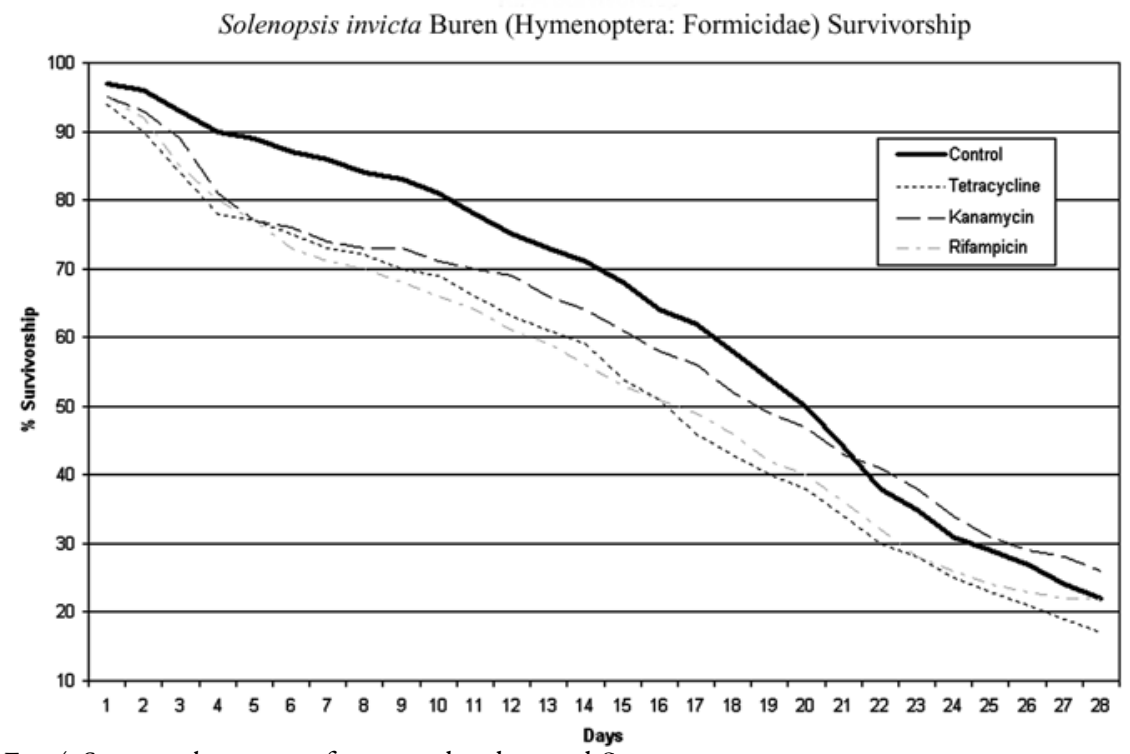

Fig. 4. Survivorship curve of untreated and treated $S$. invicta. 
erage of $74 \%$ at the end of the experiment. Whereas ants received rifampicin demonstrated a mortality range of $54-92 \%$ with an average of $78 \%$ at the end of the data collection period. The analysis indicated that in the 28 days of antibiotic treatment, significant differences occurred on six days (days: $\mathrm{P}<$ $0.0001, \mathrm{df}=27,983, \mathrm{~F}_{\text {stat }}=75.59$, treatments: $\mathrm{P}<0.0001, \mathrm{df}=3,938, \mathrm{~F}_{\text {stat }}=$ 24.81[SAS 1999]). Significant differences occurred between the control and rifampicin sets on days $8,9,10$, and 15 (Table 3). The control differed from tetracycline on days 17 and 18 . Aside from these six instances, there were no

Table 3. Significant differences detected with the Tukey-Kramer analysis between treatments.

\begin{tabular}{lll}
\hline \hline Treatment & Day & P-value \\
\hline Control vs. Rifampicin & 8 & 0.0497 \\
Control vs. Rifampicin & 9 & 0.0401 \\
Control vs. Rifampicin & 10 & 0.0426 \\
Control vs. Rifampicin & 15 & 0.0403 \\
Control vs. Tetracycline & 17 & 0.0318 \\
Control vs. Tetracycline & 18 & 0.0473 \\
\hline
\end{tabular}
significant differences between the treatments and the controls. The treatments themselves were not significantly different from each other on any days. Adult ant mortality was plotted against time (days) in Fig. 3. The confidence intervals from each day overlapped each other in every treatment and control.

\section{Microscopy}

Hindgut images (Fig. 5) revealed similar structures (Fig. 5A) with the addition of circular muscles (Fig. 5B) and bacteria (Fig. 5C) near the gut lining. Cross-sections of the hindgut (Fig. 5) and foregut/midgut (Fig. 6) did not contain any bacteriocytes. Visceral muscles in the gut epithelium were clearly visible.

Scanning electron micrographs of the foregut/midgut (Fig. 6) revealed that the structure was filled with bolus and fluids fed to the larvae by the workers. Portions of the epithelium can also be seen. Bacteriocytes were not observed in the scanning or transmission electron micrographs. Hindgut scanning micrographs showed that the hindgut had structures similar to the foregut/ midgut (Figs. 7 and 8) and no evidence of bacteriocytes. Transmission electron micrographs of the hindgut also did not contain bacteriocytes (Fig. 8).

\section{DISCUSSION}

\section{Effect of Laboratory Diet}

The study successfully inventoried bacteria in fourth-instar $S$. invicta larvae 
guts that have been lab-reared for 82 days. With the lab diet, the inventory of bacteria found in the ant guts completely differed from the one obtained when the colony was first brought in from the field (Lee et al. 2008). Such results meant that the laboratory diet contained a different bacterial inventory than the field diet. Bacteria from the diet could completely replace those in the ant guts. Comparisons between Tables 1 and 2 indicated that no common species were found among the larvae in the colonies, despite using the same colony during both studies. The bacterial inventory was strongly affected

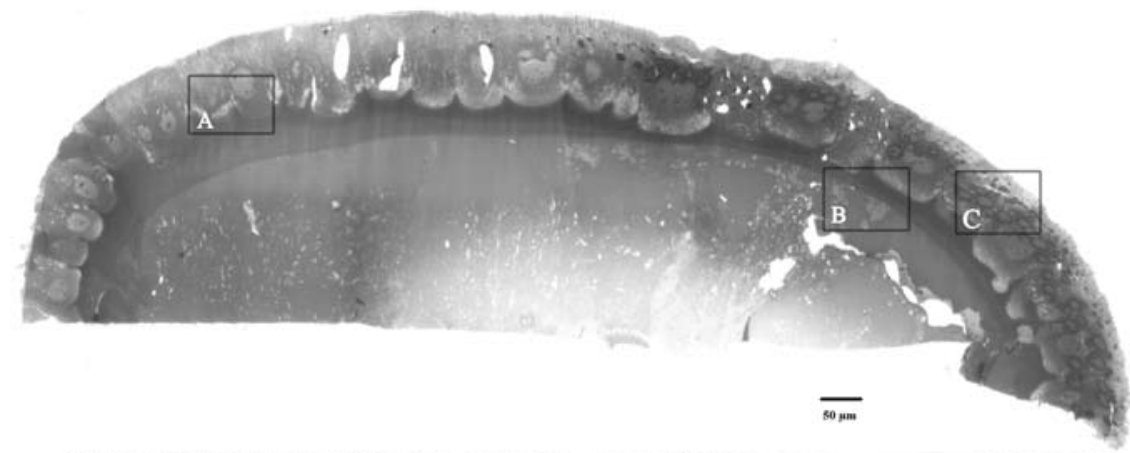

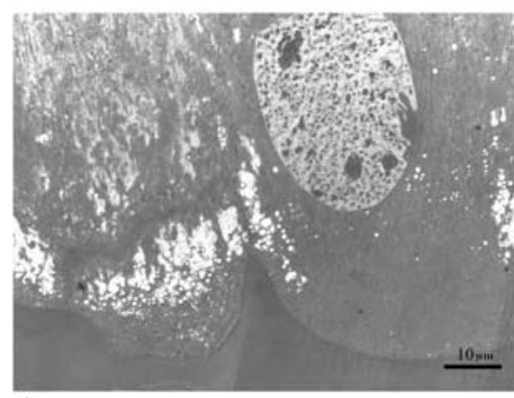

A

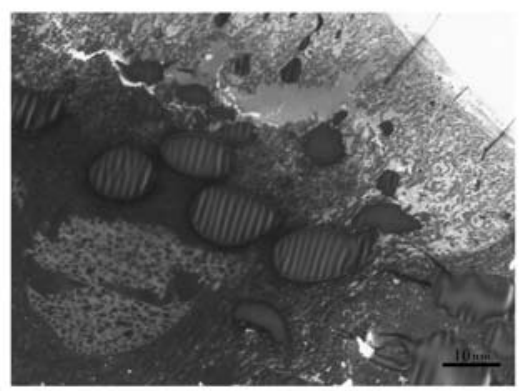

B

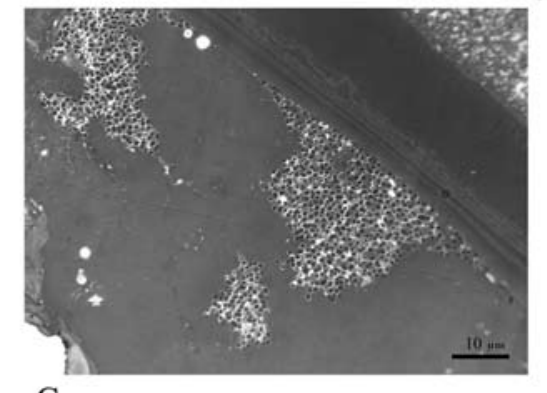

C

Fig. 5. Light microscopy cross-section images of a fourth-instar larva's hindgut. Letters represent magnified areas in the hindgut epithelium and lumen.

A. Epithelial cell in the gut wall.

B. Circular muscles in the gut wall.

C. Bacteria in the lumen near the gut wall. 
by laboratory rearing. The results suggested that bacteria associated with the laboratory diet of crickets and sugar water or the environment may have transferred to the ants. Enterobacter cloacae and Lactococcus garvieae may have been in high abundance in the laboratory diet. The presence of bacteria in the ant diet was not checked during this experiment.

Thespeciesaccumulation Chao 1 curve (Fig. 1) leveled off at sample 111 , which suggested that increased sampling should not reveal more bacteria species. Chaol indicated that between $47-96 \%$ of the actual bacterial richness was identified. The percentage range was obtained by dividing the number of unique species by the lower and upper bounds of the Chaol estimator 95\% confidence interval. Rarespecies based estimator Jack 1 indicated that between $56-77 \%$ of the bacterial richness was identified.

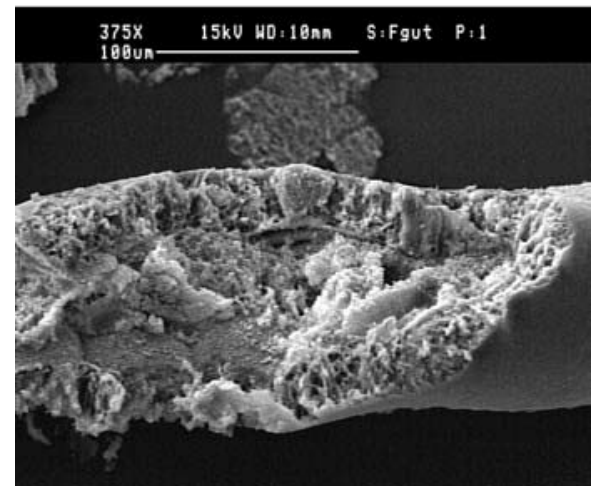

Fig.6.Scanningelectron micrograph of the foregut/ midgut of a fourth-instar larva longitudinal section.

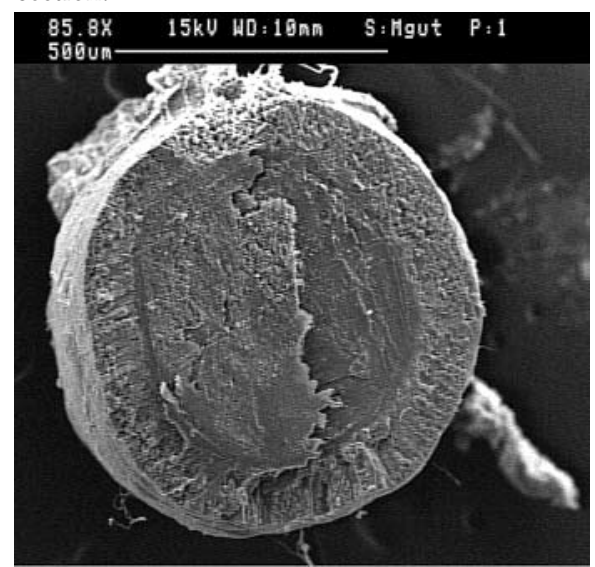

Fig.7.Scanningelection micrograph of the hindgut of a fourth-instar larva. Both the ACE and ICE estimators indicated that about $47-57 \%$ of the bacterial richness was identified.

Bacteria from this colony were not closely related to the symbionts of carpenter ants, aphids, and tsetse flies, which formed a unique and wellsupported branch in the phylogenetic tree (Fig. 2). Tree ants (Tetraponera $s p$.) symbionts were found in neighboring clades.

The results suggested that bacteria associated with the laboratory diet of crickets and sugar water or the environment may have transferred to the ants. This conclusion is supported by the work of Jouvenaz et al. (1996). They 
contaminated food with Serratia marcescens and fed it to fourth-instar larvae. The $S$. marcescens were isolated from all tested larval midguts. Data from Lee et al. (2008) and that of Jouvenaz et al. (1996) support the conclusion that the bacteria in the guts of fourth-instar fire ant larvae are composed of environmental bacteria.

Enterobacter cloacae are commonly found in human and animal feces and are not an enteric pathogen (Bergey 1984). However, E. cloacae are an
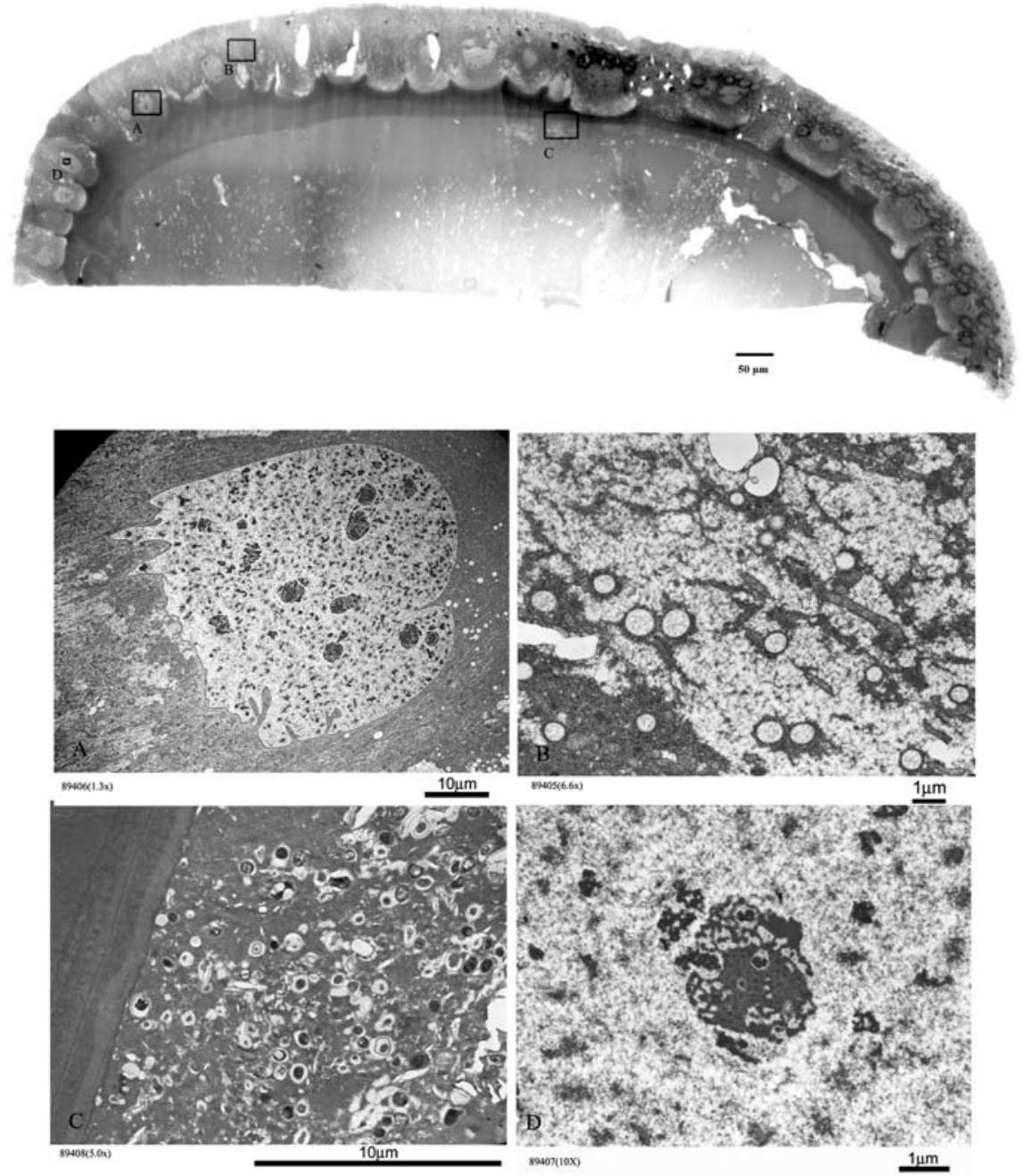

Fig. 8. Cross-section of the hindgut of a fourth-instar larva. 
opportunistic pathogen capable of infecting the urinary tract, sputum, and respiratory tract of animals. As a fecal bacterium it is very common in water, sewage, and soil (Bergey 1984). Enterobacter cloacae's presence in the inventory was not surprising since crickets could have easily picked them up as they foraged for food or simply by interacting with the environment. Attempts were made to establish how the crickets were fed and reared by the supplier (Fluker Farms, Port Allen, La) but the company never responded.

Other identified bacteria in the inventory fell into the same niche as E. cloacae. These include Enterococcusfaecalis, Klebsiella spp., uncultured bacterium rRNA238, and uncultured bacterium P2D1-740. Both uncultured bacteria identified in this study had similar DNA sequences to fecal bacteria.

Lactococcus garvieae was the second most abundant bacteria in the inventory. Identified as a major pathogen of fish (Eldar et al. 1999) and a causative agent for bovine mastitis (Bergey 1984), this bacterium may be present in soil and contaminated water. All three field-fresh colonies examined did not have a single clone representing $L$. garvieae. The bacterium's presence clearly came from the laboratory food or laboratory environment. Preliminary studies conducted while examining the bacterial community of whole larvae that have been reared in the lab for two weeks also had large numbers of $L$. garvieae in their systems. This study was not the first one to identify L. garvieae in S. invicta . Peloquin \& Greenberg (2004) and Li et al. (2005) found this bacterium in their culture-dependent methods. Studies done by these researchers had one thing in common with our lab-reared colony. All of the colonies do not appear to be fresh from the field.

\section{Antibiotic trials}

Results from the antibiotic trials indicated no significant difference in overall mortality between control and treated colony fragments. Worker ant mortality was not visibly affected by clearing most of the bacteria in the guts of fourth-instar larvae. Likewise, larvae mortality was not visibly affected either. There were no larval skins found in the boxes, indicating that cannibalism did not occur. Both larvae and workers appeared healthy during the duration of the study, which suggests that dosage of the drugs used had no adverse affects on the ants. All of the ants were both active and quick and did not appear sluggish or slow. Bacteria with drug resistance genes were the only factor that may have affected the results. 
When similar antibiotic experiments were done on Cephalotes pusillus, adult mortality effects were observed after 24 hrs. Jaffe et al. (2001) concluded that ant mortality was probably caused by the antibiotic killing one, some, or all of the associated bacteria that are susceptible to kanamycin. Some of the bacteria in the digestive tract of $C$. pisillus are essential to the ant, probably forming a symbiotic relationship with the host (Jaffe et al. 2001). Our study not only included kanamycin, but also tetracycline and rifampicin and found no significant differences in daily mortality in the ants except in six cases. Time periods before and after these days were no different from each other and the control. Differences found were determined to be outliers and the treatments and control were not significant different from each other. Even though the presence of antibiotic-resistant bacteria may be available in this fire ant population, it is assumed that the majority of the bacteria in the larvae were not antibiotic resistant or if they were, they would not be resistant to all three antibiotics tested.

From the data it would appear as though there are no obligate endosymbiotic bacteria in the guts of fourth-instar fire ant larvae that are important for survival. However, there are many species that are transient in nature. Molecular data suggests that all bacteria inventoried from larvae was environmental in origin and were present in the guts because they were consumed by the ants (Lee et al. 2008). A broad spectrum antibiotic that has been shown to have an effect on $C$. pusillus mortality had no significant effect on $S$. invicta . Additionally, two other antibiotics demonstrated no adverse affects on $S$. invicta workers and larvae.

However, Li et al. (2005) found that certain bacteria (all but an uncultured bacterium and Bacillus punilus) isolated from $S$. invicta were resistant to antibiotics (ampicillin, chloramphenicol, doxycycline, erythromycin, gentamycin, kanamycin, kalidixic acid, neomycin, spectinomycin, streptomycin, tetracycline, or zeocin). They found one bacteria that was resistant to all the drugs tested. In their study, most were susceptible to various drugs and only two were resistant to both kanamycin and tetracycline ( $\mathrm{Li}$ et al.2005). These data suggest that the larval guts in this study may not have been rendered completely bacteria free. In the future, an antibiotic cocktail may be necessary to test on the ants since the ants would be closer to being bacteria-free. 


\section{Microscopy}

The absence of specialized structures with obligate endosymbionts is evidence that bacteria in fourth-instarlarvae are present because they were brought by the workers and fed to the young. Only epithelial and muscle cells were found in the lining of guts of $S$. invicta larvae. Gut lumen contained bacteria, fluids, and bolus. Fourth-instar larvae are believed to be the only members in a $S$. invicta colony that can digest solid food. Such abilities may be due to glands in the gut that secrete digestive compounds instead of specialized gut organisms that facilitate the process like protozoans in termites. Experimental data from the study provided evidence of environmental sources of bacteria in S. invicta . Microscopy did not find bacteria in bacteriocytes or even bacteriocytes themselves; bacteria were found in the lumen of the hindgut.

Carpenter ants may be capable of functioning as herbivores who subsist on a diet of sugary water causing the ants to rely on their obligate endosymbionts. Candidatus Blochmannia floridanus, the obligate endosymbiont in carpenter ants, is able to supply nitrogen and sulfur compounds to the host through the host's metabolic machinery (Gil et al. 2003). The endosymbiont makes it possible for the carpenter ant to feed exclusively on sugars and still be able to survive and multiply by providing nitrogen and sulfur. An alternative feeding strategy may not be present or necessary in S. invicta .

Though coadapted bacteria and bacteriocytes were not found in the guts of fourth-instar larvae, such specialized organisms may be present elsewhere in the ant. Coadapted endosymbionts may be present in the hemolymph, fat body, or other organs in fourth-instar larvae. Adult ants may contain coadapted endosymbionts that help the colony survive by providing nutrients or other useful compounds.

The reason for the lack of obligate symbiosis may be due to diet. S. invicta's diet consists of diverse food items and rarely focuses on a narrow nutrient source such as honeydew. Workers also collect honeydew and will forage for sweets, proteins, and fats (Vinson \& Sorenson 1986). Fire ants acquire all their essential nutrients from their diet. Unlike termites, Tetraponera spp., and Camponotusfloridanus, $S$. invicta may not need specialized obligate symbionts to supply it with supplemental nutrients. $S$. invicta gut bacteria communities are contributed by substances ingested from the environment. 


\section{CONCLUSION}

Observations from this study corroborated the findings of (Lee et al. 2008) and relied on culture-independent techniques, particularly 16 S rDNA sequencing. Ants in captivity completely change their gut bacterial diversity strongly supports the conclusion that gut bacteria are environmental in origin. Studies performed with antibiotics and microscopy support the conclusion drawn from the $16 \mathrm{~S}$ rDNA sequencing work. The null hypothesis that fourth-instar larvae do not contain coadapted bacteria and that all the bacteria identified were environmentally derived was supported in every case. Bacteria in the fourth-instar larvae were present because they were consumed with food sources. From molecular data, a different list of bacteria from each colony with different branching and clustering among bacterial clades in the phylogenetic trees was found. Different bacterial diversity and evenness was found in all colonies, which provided evidence against the idea of the presence of obligate endosymbionts in $S$. invicta guts. Direct methods described above did not indicate the presence of endosymbionts. Likewise, indirect approaches came up with the same results.

If the fire ants had obligate endosymbionts then clearing (or nearly clearing) the guts with antibiotics should have a detrimental effect on them similar to that observed by Jaffe et al. (2001) in C.pusillus. Clearing out endosymbionts with antibiotics increased mortality in C.pusillus. The three broad-spectrum antibiotics that were tested provided no significant differences in ant mortality when compared to the untreated controls. Following this method of study was light and electron microscopy. Unlike Sauer et al. (2002), who found bacteriocytes in carpenter ants, our study did not find bacteriocytes in the midgut epithelium of fire ants. Microscopic observations did not locate any bacteriocytes in fourth-instar $S$. invicta larvae. All identified bacteria appeared to have been derived from the food or the environment.

Though coadapted bacteria and specialized bacteriocytes were not found in the guts of fourth-instar larvae, such specialized organisms may be present elsewhere in the ant. Coadapted symbionts may exist in other parts of the larvae's body or in other stages of development. However, the fourth-instar larvae remains the primary stage responsible for the digestion of solid food and the source of nutrients for the queen and adult workers through the production 
of chymotrypsin-like and elastase-like proteinases (Whitworth et al. 1998). In termite and carpenter ant examples, nutrients and enzymes that facilitate food digestion can be from obligate endosymbionts. Solenopsis invicta may have other types of obligate endosymbionts in the form of protozoans and fungi in their systems However, based on the results, these proteinases are likely from the gut glands of $S$. invicta .

\section{ACKNOWLEDGMENTS}

We thank Cindy Henk and Ying Xiao from Louisiana State University's Socolofsky Microscopy Center for her help in preparation of the ants for microscopy. The authors are grateful for helpful comments on this manuscript from Drs. Fred Enright, Claudia Husseneder, Christopher Carlton, Gregg Henderson, and Lane Foil.

\section{REFERENCES}

Altschul, S.F., W.Gish, W. Miller, E.W. Myers \& D.J. Lipman 1990. Basic local alignment search tool. Journal of Molecular Biology 215: 403-410.

Banks, W.A., C.S. Lofgren, D.P. Jouvenaz, C.E. Stringer, P.M. Bishop, D.F. Williams, P.D. Wojcik \& B.M. Glancey 1981. Techniques for collecting, rearing and handling imported fire ants. U.S. Department of Agriculture Science and Education Administration Advances in Agricultural Technology AAT-S-21.

Bergey, D.H. 1984. Bergey's manual of systematic bacteriology, Volume 1. Lippincott Williams and Wilkins.

Caetano, F.H. 1989. Endosymbiosis of ants with intestinal and salivary gland bacteria. In Schemmler W, editor. Insect endocytobiosis, morphology, physiology, genetics, and evolution, pp. 58-76. CRC Press.

Cassill, D.L \& W.R. Tschinkel 1995. Allocation of liquid food to larvae via trophallaxis in colonies of the fire ant, Solenopsis invicta. Animal Behavior 50: 801-813.

Colwell, R.K., C.X. Mao \& J. Chang 2004. Interpolating, extrapolating, and comparing incidence-based species accumulation curves. Ecology 85: 2717-2727.

Colwell, R.K. 1994-2004. EstimateS: statistical estimation of species richness and shared species from samples. Available online: http://viceroy.eeb.uconn.edu/estimates. [Persistent URL: (http://purl.oclc.org/estimates).]

Eldar, A., M. Goria, C. Ghittino, A.Zlotkin, \& H. Bercovier 1999. Biodiversity of Lactococcus garvieae strains isolated from fish in Europe, Asia, and Australia. Applied Environmental. Microbiology 65: 1005-1008.

Gil, R, F.J. Silva, E. Zientz, F. Delmotte, F. González-Candelas, A. Latorre, C. Rausell, J. Kamerbeek, J. Gadau, B. Hölldobler, R.C.H.J. Van Ham, R. Gross \& A. Moya 2003. The genome sequence of Blochmannia floridanus: Comparative analysis of reduced genomes. Proceedings of the National Academy of Sciences 100: 9388-9393. 
Jaffe, K., F.H.Caetano, P. Sanchez,J.V.Hernandez,L.Caraballo,J.Vitelli-Flores, W.Monsalve, B. Dorta \& V.R. Lemoine 2001. Sensitivity of ant (Cephalotes) colonies and individuals to antibiotics implies feeding symbiosis with gut microorganisms. Canadian Journal of Zoology 79: 1120-1124.

Jouvenaz D.P., C. Jeffrey, J.C. Lord \& A.H. Undeen 1996. Restricted ingestion of bacteria by fire ants. Journal of Invertebrate Pathology 68: 275-277.

Kumar, S., K. Tamura \& M. Nei 2004. MEGA 3: Integrated Software for Molecular Evolutionary Genetics Analysis and Sequence Alignment. Briefings in Bioinformatics 5: 150-163.

Lane, D.J. 1991. 16S/23S rRNA sequencing. In: Stackebrandt E, Goodfellow M, editors. In: Nucleic acid techniques in bacterial systematics, pp. 115-175. John Wiley and Sons.

Lee A., C. Husseneder \& L.M. Hooper-Bùi 2008. Culture-independent identification of gut bacteria in fourth-instar red imported fire ant, Solenopsis invicta Buren, larvae. Journal of Invertebrate Pathology 98: 20-33.

Li, H.W., F. Medina, S.B. Vinson \& C.J. Coates 2005. Isolation, characterization, and molecular identification of bacteria from the red imported fire ant (Solenopsis invicta) midgut. Journal of Invertebrate Pathology 89: 203-209.

Liu, W., T.L. Marsh, H. Cheng \& L.J. Forney 1997. Characterization of microbial diversity by determining terminal restriction fragment polymorphism of genes encoding $16 \mathrm{~S}$ rRNA. Appied Environmental Microbiology 63: 4516-4522.

Peloquin ,J.J. \& L. Greenberg 2003. Identification of midgut bacteria from fourth instar red imported fire ant larvae, Solenopsis invicta Buren (Hymenoptera : Formicidae). Journal of Agricultural and Urban Entomology 20: 157-164.

Sapp, J. 1994. Evolution by Association, Oxford University Press.

Sauer, C., D. Dudaczek, B. Hölldobler \& R. Gross 2002. Tissue localization of the endosymbiotic bacterium "Candidatus Blochmannia floridanus" in adults and larvae of the carpenter ant Camponotus floridanus. Applied Environmental Microbiology 71: 8784-8794.

Schowalter ,T. 2000. Insect Ecology: an ecosystem approach. Academic Press.

Urakawa, H.K., K. Kita-Tsukamoto \& K. Ohwada 1999. Microbial diversity in marine sediments from Sagami Bay and Tokyo Bay, Japan, as determined by $16 \mathrm{~S}$ rRNA gene analysis. Microbiology 145: 3305-3315.

Vinson, S.B. \& L. Greenberg 1986. The biology, physiology, and ecology of imported fire ants. In: Vinson SB, editor. Economic Impacts and Control of Social Insects, pp. 193226. Praeger Publishers.

Whitworth, S.T., M.S. Blum \& J. Travis 1998. Proteolytic enzymes from larvae of the fire ant, Solenopsis invicta isolation and characterization of four serine endopeptidases. Journal of Biological Chemistry 273: 14430-14434.

Yurman, D. \& M.G. Dominguez-Bello 1993. Bacteria present in the gut of two Neotropical Cephalotini ants, Cephalotes atratus and Zacryptocerus pussillus. Folia Microbiologica 38: 515-518. 